\title{
Peertechz
}

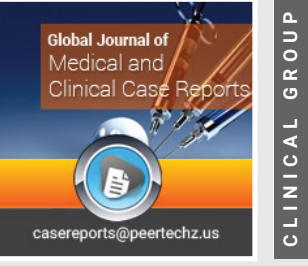

Research Article

\section{Anatomical evaluation of} the craniometric points and dimensions among adult's populations of the South-Eastern Nigerians and its implication for intracranial surgical procedures

\author{
David Lekpa Kingdom ${ }^{1}$ and Vidona Willy Barinem ${ }^{2 *}$ \\ 'Department of Anatomy, University of Port Harcourt, Rivers State, Nigeria \\ 2Department of Anatomy, Edo State University Uzairue, Edo State, Nigeria
}

Received: 19 October, 2021

Accepted: 26 October, 2021

Published: 27 October, 2021

*Corresponding author: Vidona Willy Barinem, Department of Anatomy, Edo State University Uzairue, Edo State, Nigeria, E-mail: wills_bills@yahoo.com

Keywords: Craniometric points; Intracranial; Surgical procedures; Age group; Cranial parameters

Copyright: (@) 2021 David LK, et al. This is an openaccess article distributed under the terms of the Creative Commons Attribution License, which permits unrestricted use, distribution, and reproduction in any medium, provided the original author and source are credited.

https://www.peertechzpublications.com

Check for updates

\section{Abstract}

Background: The understanding of Craniometry with its associated craniometric points and dimensions have found immense applicable relevance in anthropology and neuroscience, ranging from growth determination, estimation of cranial deformities, personal biological profile identification and facial reconstructive surgeries, analysis of evolution of the human species in archeology as well as age variations.

Objective: The aim of this study was to evaluate the craniometric dimensions among adults' subjects in Eastern Nigerian State.

Methods: Research data was collected from Computed Tomography scans in the Radiological Department of Federal Medical Centre, Umuahia, Nigeria with strict adherence to inclusive and exclusive factors. A total number of 150 human CT scans were used in the findings. Craniometric parameters were calculated - derived from the two and three coordinate points for linear and angular measurements respectively.

Results: Results revealed that age group 36-45 had the lowest cranial parameters and age group 56-65 had the highest cranial parameters.

Conclusion: It was concluded that cranial parameters does not increase as age increases throughout life. The study findings will be useful to the anatomists, anthropologists and neuroscientists.

\section{Introduction}

Cranial index variations between and within population have been attributed to a complex interaction between genetic and environmental factors. Knowledge of the cranium of either a dry human skull or of a living being through morphometric and non-morphometric studies are very helpful for the study and comparison of populations with various fundamental differences such as in personal identification of individuals from basic biological profile of sex, age, ethnicity or geographic.

According to Kanchan, et al. [1] crania are also the most commonly used skeletal elements in population studies because they are known to be more genetically driven and less affected by environmental factors. Craniometry evaluated by computed tomography and other radio-imaging and radiographic techniques are now a useful and modern tool to anatomists, anthropologists and neuroscientists accepted as a standard protocol for clinical diagnosis and surgical procedures or medico-legal examinations as identified by Christensen and Crowder [2]. However, anatomical landmarks of skulls can be established by using other various methods such as direct physical measurement, $\mathrm{x}$-ray and $2 \mathrm{D}$ or $3 \mathrm{D}$ (third dimension) imaging technology. When investigating craniometric variations, two main types of data in either two or three-dimensional views are collected. Both data requires locating a suite of craniometric points and dimensions $[3,4]$. 
Three dimensional data is specifically useful because it allows for the $\mathrm{x}$ and $\mathrm{y}$ coordinates from the traditional interlandmark distances to be analyzed spatially with respect to the $\mathrm{z}$ coordinates.

Cranial volume as an aspect of dimension equally expresses several degrees of growth and development and permits critical evaluation of unusually large, small or misshapen crania as noted by Haack and Meihoff [5]. The application of craniometric data from cranial morphology in mainstream science today is used to analyze the evolution of the human species in archeology as population differentiation has been explored showing that various cranial characteristics are responsible for both inter and intra-regional differences within a geographical region [6]. Measurements of craniofacial complex are useful in comparison of the patient with a normal reference group, so that the differences between the patient's actual craniofacial and dento-facial relationships and those expected for his/her racial or ethnic group are revealed [7]. The need to produce and update the various craniofacial dimensional standards among a unique populations is central to this study, hence the aim of this study is to evaluate the craniometric dimensions among adults' subjects in Eastern Nigerian State, with the objective of determining the variations of craniometric points among adult age groups using the radio-imaging tool of computed tomography.

\section{Materials and methods}

\section{Study design}

This is a prospective study that was carried in a multi specialist government tertiary health facility using computed tomography data taken from May 2020 to July 2021.

\section{Sample inclusion}

Individuals between the age of 25 to 60 years with no incidence of head trauma or abnormality, loss of teeth from the maxilla or chronic illness that might affect the cranium were used for the study while individuals with anatomical deformities and children were avoided in the collection of data.

The data for this research included one hundred (150) Computed Tomography scan results collected from a Computed Tomography SCAN's diagnostic centers in Umuahia, Nigeria.

Computed Tomography (CT) was used due to its accuracy of verification of surface landmark placement relative to bony landmark as well as easy measurability and reproducibility of paired dimensions. CT scan also has the advantage of sectioning images in the same section and archiving them in DICOM (Digital Imaging and Communications in Medicine) format.

\section{Computed tomography data acquisition}

During CT scan, the individual lie on a table structure known as gantry. The gantry slowly passes through the center of a large $\mathrm{x}$-ray machine. During some test the individual receives dye for contrast. Patients were scanned and the CT data were processed in a computer workstation at the department. A spiral computed tomography scanner (SIEMEN) was used to obtain data from 150 crania. The CT scan acquisition was performed with $1.5 \mathrm{~mm}$ slice thickness and reconstruction was done with $1.0 \mathrm{~m} 2 \mathrm{~m}$ slice thickness. All the CT data was recorded using DICOM 3.0 as a medical image file format into CD-ROM and subsequently imported to the medical imaging software (MIMICKS) - materialized N.V Belgium. The segmentation techniques was used to identify the region of interest of the computed tomography image based on Hounsfield unit. The selected regions were calculated into 3D modem which enabled the determination of the 3D Craniometric data. During each scanning, each subject was placed in a supine position. Axial scanogram was obtained from the setting such that the tube voltage was $120 \mathrm{KVP}$ and tube current was $52 \mathrm{~mA}$, with 0.58 rotation time and $1 \mathrm{~mm}$ slice thickness.

\section{Measurement of $\mathbf{3 d}$ craniometric data}

Craniometric data was determined by defining the anatomical landmarks which can be classified as median and bilateral types $[8,9]$. The mean landmarks are approximately located on sagittal plane. All dimensions/landmarks used were based on traditional definitions with modification into $3 \mathrm{D}$ model. The most prominent anatomy in $2 \mathrm{D} / 3 \mathrm{D}$ views were selected to state the proper position of each anatomical landmark. However, craniometric parameters were calculated - derived from the two and three coordinate points for linear and angular measurements respectively.

\section{The craniometric points includes}

Glabella (GL): The most anterior point of frontal bone between supraorbital in the sagittal plane. Bregma (BR) - the crossing of the coronal and sagittal sutures on the top of the skull. Opisthocranium (OPC) - the most posterior point in midline of inion bone which length of the skull is maximum when measure from Glabella point.

Nasion (NA): The intersection point of the internasal and frontonasal sutures in the sagittal plane.

Basion (BA): The most anterior point of the great foramen magnum in the sagittal plane.

Craniometric dimensions/landmarks includes: Occipal Length (GOL), Basion Nasion Length (BNL), Basion Bregma Height (BBN), Nasion Bregma Cord (NBC), Bregma Lambda Cord (BLC), Lambda Opisthion Length (LOL), Basion Prosthion Length (BPL).

Only one investigator located the entire dimensions in the skulls to avoid uncertainty and wide variations if any of intra-observer. The anatomical landmarks were used to obtain 150 Craniometric parameters. There were considerations limited to only complete union of the glabella occipal length, basion nasion length, basion bregma height, nasion bregma cord, bregma lambda cord, lambda opisthion length, basion prosthion length sutures instead of taking into account other scoring system of suture closure and compared with standard data mentioned in different texts and previous studies. 


\section{Statistical analysis}

The measurement data were expressed in Microsoft Excel and then exported to SPSS version 20.0 for the statistical analysis and interpretation by descriptive statistics reported in form of comparism of the mean values and mean difference, standard deviation and confidence interval in respect to the various landmarks. In order to distinguish Craniometric parameters of each age, analysis of variance was utilized for analysis. The investigation of different Craniometric data between the cranium values was analyzed with their degree of freedom (df), confidence interval (CI). A p-value $<0.05$ was considered to be statistical significant difference.

\section{Results and discussion}

The table describes the confidence interval for the mean (lower and upper bound), minimum value and maximum value of the length for each group with the confidence interval for each group in each column following an alpha $(\alpha)$ level of significance of 0.05 Table 1 .

From the distribution of means among the various group dimensions it is observed that the difference between each group is not large but rather a difference with a few number which ranges from 1 to at least 50 as seen in Tables 2,3 which is similar to work done by Vidona, et al. [10].

This research work of significance value of 0.00 means that the research is $90 \%$ confident indicating the results are accurate. Therefore, the test is statistically significant which

\begin{tabular}{|c|c|c|c|c|c|c|c|c|}
\hline $\begin{array}{l}\text { Length (Lower } \\
\text { Bound) }\end{array}$ & GOL & BNL & BBH & NBC & BLC & LOL & BPL & TOTAL \\
\hline $\mathrm{N}$ & 150 & 150 & 150 & 150 & 150 & 150 & 150 & 1050 \\
\hline Mean & 173.46 & 115.26 & 123.25 & 128.14 & 117.34 & 99.89 & 124.53 & 125.98 \\
\hline SD & 13.860 & 8.404 & 13.317 & 9.313 & 10.987 & 12.535 & 9.215 & 23.982 \\
\hline Standard Error & 1.132 & .686 & 1.087 & .760 & .897 & 1.023 & .752 & .740 \\
\hline $\begin{array}{l}95 \% \\
\text { Confidence } \\
\text { Interval for } \\
\text { Mean }\end{array}$ & 171.22 & 113.90 & 121.10 & 126.64 & 115.57 & 97.87 & 123.05 & 124.53 \\
\hline $\begin{array}{l}\text { Length (Upper } \\
\text { Bound) }\end{array}$ & GOL & BNL & $\mathrm{BBH}$ & NBC & BLC & LOL & $\mathrm{BPL}$ & TOTAL \\
\hline $\begin{array}{c}95 \% \\
\text { Confidence } \\
\text { Interval for } \\
\text { Mean }\end{array}$ & 175.70 & 116.62 & 125.40 & 129.64 & 119.11 & 101.92 & 126.02 & 127.44 \\
\hline Minimum & 144 & 94 & 98 & 102 & 90 & 80 & 99 & 80 \\
\hline Maximum & 199 & 139 & 171 & 149 & 142 & 169 & 150 & 199 \\
\hline
\end{tabular}

Table 2: Comparing groups mean.

\begin{tabular}{|c|c|c|c|c|c|c|c|}
\hline $\begin{array}{c}\text { Parameters } \\
\text { in age }\end{array}$ & GOL & BNL & BBH & NBC & BLC & LOL & BPL \\
\hline $25-35$ & 31.2228 & 20.7468 & 22.185 & 23.0652 & 21.1212 & 17.9802 & 21.6864 \\
\hline $36-45$ & 20.8152 & 13.8312 & 14.78 & 15.3768 & 14.0808 & 11.9868 & 14.4576 \\
\hline $46-55$ & 52.038 & 34.578 & 36.578 & 38.442 & 35.202 & 29.967 & 36.144 \\
\hline $56-65$ & 69.384 & 46.104 & 46.104 & 51.256 & 46.936 & 39.956 & 48.192 \\
\hline
\end{tabular}

Table 3: Anova Test showing length values between and within groups.

\begin{tabular}{|c|c|c|}
\hline Anova Test & Between groups & Within groups \\
\hline S/N & 150 & 150 \\
\hline DF & 6 & 1043 \\
\hline SS & 470793.851 & 132541.840 \\
\hline MS & & 127.078 \\
\hline F-RATION & 617.464 & \\
\hline Significant value & 0.00 & \\
\hline
\end{tabular}

means that the cranium results have an acceptable amount of error. This also agrees with research of Craniometry patterns of Nigerians and its correlation with chronological age [10].

\section{Key}

\section{SD: Standard Deviation}

SS: Sum of Squares

MS: Mean Sum of Squares

F-ratio: Mean sum of squares of treatment / mean sum of square of error

$\mathrm{N}$ : Number of sample

DF: Degree of Freedom.

Most of the data from the length of the dimensions differ from values of work done in India [11] which be probably be due to genetic, racial, developmental factors, geographical location and dietary habits. The study has demonstrated an advanced technique based on computed tomographic and medical imaging methods, which is very useful to analyze the craniometric study digitally without physical measurement and destruction to the specimen as was done in the stone centuries back as noted in a material by Leaky [12]. Age of the cranium skulls suture of the dimensions were matching with standard data given in the table that was analyzed.

Comparing group mean values of GOL, BNL, BBH, NBC, BLC, LOL and BPL parameters, the ages between 56-65 revealed the highest values across groups whereas the ages between 36-45 had the lowest values amongst the groups. On the other hand, the ages between 46-55 years had a mean values greater than the ages between 25-35 years.

\section{Conclusion}

Cranial Parameters decreases between ages 36-45 among South-Eastern Nigerians. This could be as result of the assertion that cranial length or maximum cranial reaches its size in adults around the age of 10 for females and about 14 years for males according to Farkas, et al. [13,14]. The implication of this outcome is therefore for clinicians to understand the cranial dimensions and its growth length corresponding to adults' population within the age brackets investigated to help guide diagnosis and interpretations for cranial related cases. Recommendation would be for more such studies to understand the effect of genetics on the cranial shapes in 
different population groups and its geometric morphometric analysis as well as that comparing data with different nationalities will be important in determining the structural craniometric properties for social diversity. Therefore the localization of these cranial dimensions will help in identifying vital intracranial structures lying within such dimensions and hence the implication in what is referred to as surgical tailoring as well as in correlating these normal structural dimensions with pathological or cranial abnormalities subcortically.

\section{References}

1. Kanchan T, Krishan K, Gupta A, Acharya J (2014) A Study of Cranial Variations Based on Craniometric Indices in a South Indian Population. J Craniofac Surg 25: 1645-1649. Link: https://bit.ly/3GIOKrc

2. Christensen AM, Crowder CM (2009) Evidentiary standards for forensic anthropology. J Forensic Sci 54: 1211-1216. Link: https://bit.ly/3GmLpZ2

3. Golalipour MJ, Haidari K, Jahanshahi M, Frahani MR (2006) The shapes of head and face in normal male newborns in South-East of Caspian Sea (IranGorgan). Anatomy Society India 52: 28-31. Link: https://bit.ly/3EedTSM

4. Coon CS (1971) A fossilized human mandibular fragment from Kangatotha, Kenya, East Africa. Am J Phys Anthropol 34: 157-163. Link: https://bit.ly/3EkxsZQ

5. Haack DC, Meihoff EC (1971) A method for estimation of cranial capacity from cephalometric Roentgenograms. Am J Phys Anthropol 34: 447-452. Link: https://bit.ly/2ZgHVGh
6. Stephan CN, Simpson EK (2008) Facial soft tissue depths in craniofacia identification (part I): an analytical review of the published adult data. $J$ Forensic Sci 53:1257-1272. Link: https://bit.ly/3nr7ay9

7. Stewart RF, Edgar H, Tatlock C, Kroth PJ (2008) Developing a standardized cephalometric vocabulary: choices and possible strategies. J Dent Educ 72 989-997. Link: https://bit.ly/3jCBGnH

8. Tyebkahan G (2003) Declaration of Helsinki. The ethical cornerstone of human clinical research. Indian J Dermatol Venereol Leprol 69: 245-247. Link: https://bit.ly/3GnZrt5

9. Shah GV, Jadhav HR (2004) The study of cephalic index in students of Gujarat Journal of Anatomy Society India 53: 25-26. Link: https://bit.ly/2ZzcTK6

10. Vidona WB, Oviosun A, David LK (2021) Craniometry Patterns of Nigerians and its correlation with chronological age. Journal of Phylogenetics and Evolutionary Biology 9: 212. Link: https://bit.ly/3pHzTkT

11. Ramamoorthy B, Pai MM, Prabhu LV, Muralimanju BV, Rai R (2016) Assessment of craniometric traits in South Indian dry skulls for sex determination. J Forensic Leg Med 37: 8-14. Link: https://bit.ly/3Eiq80w

12. Leaky LSB (1935) The Stone Age races of Kenya. (1st Edition). Oxford University Press, London. 150. Link: https://bit.ly/3pDJKbt

13. Farkas LG, Posnick JC, Hreczko TM (1992) Anthropometric growth study of the head. The Cleft Palate-Craniofacial Journal 29: 303-308. Link: https://bit.ly/3viTt1j

14. Hiernaux J (1968) Bantu expansion: the evidence from physical anthropology confronted with linguistic and archaeological evidence. Journal of African History 9: 505-515. Link: https://bit.ly/3CkJX6T

\section{Discover a bigger Impact and Visibility of your article publication with} Peertechz Publications

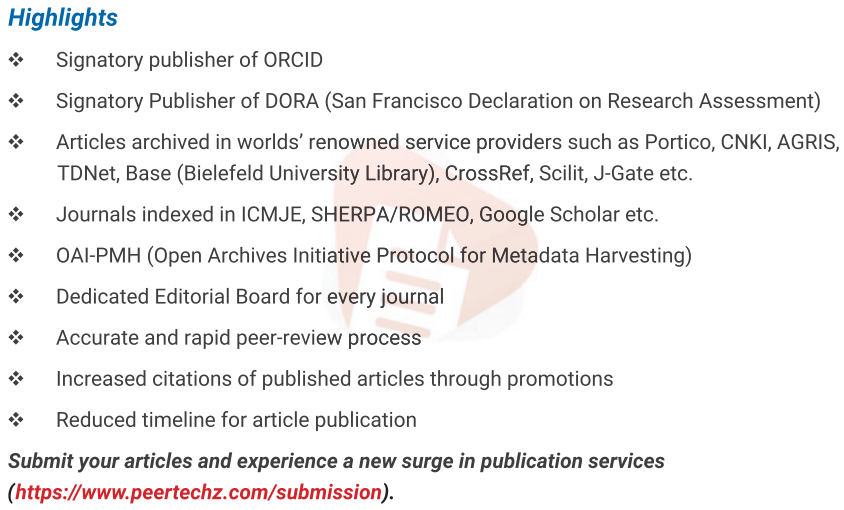

Peertechz journals wishes everlasting success in your every endeavours. 